\title{
Diarrhoea due to sucrase and isomaltase deficiency
}

\author{
I. J. PINK \\ From the Gastrointestinal Laboratory, St. Thomas' Hospital, London
}

EDITORIAL COMMENT This paper draws attention to the need to consider this diagnosis in adults as well as in children. Characteristic radiological changes in the small intestine may occur when a barium meal is given with sucrose added to it.

Diarrhoea due to deficiency of the intestinal disaccharidases is now well recognized in children (Weijers, van de Kamer, Dicke, and Ijsseling, 1961; Townley, 1966; Anderson, Messer, Townley, and Freeman, 1963) and is becoming increasingly recognized in adults (Haemmerli, Kistler, Ammann, Marthaler, Semenza, Auricchio, and Prader, 1965). Most of these patients have a deficiency of intestinal lactase, and only rarely is the diarrhoea due to deficiency of other disaccharidases, sucrase and isomaltase. The purpose of this paper is to report another case of diarrhoea in an adult due to deficiency of intestinal sucrase and isomaltase because of the apparent rarity of this condition and because there are a few features of this case which may add to our knowledge of the disease.

\section{CASE REPORT}

The patient was aged 23, and a State Registered Nurse, when she presented to the Out-Patient Department in September 1965. She complained of diarrhoea, passing two to five loose, bulky stools per day. As an infant she was well, breast fed until aged 4 months, and then weaned. Although there was then war-time sugar rationing her mother states that there was no shortage of sugar in her household, and that our patient was fed normal amounts of sugar. She had no bowel symptoms until aged 4-5 years, when she began to pass two to five stools per day, and this had continued until the present time. She had occasional exacerbations of diarrhoea when she passed up to 12 stools per day. The diarrhoea was sometimes associated with rumblings in the abdomen, and with mild colicky lower abdominal pain. She had noticed that the symptoms were worse one to three hours after she had eaten a bar of chocolate or other very sweet foods, and she tended to avoid these.

She had been investigated as a possible case of coeliac disease when aged 5 years. At the age of 14 she had a laparotomy for a possible torsion of the sigmoid colon, and had an appendicectomy.

Her parents are both alive and well and not related She has three siblings none of whom have any diarrhoea.

Examination revealed a fit-looking young woman of normal height and weight. She had the abdominal scar of the laparotomy, but no other abnormality was found.

INVESTIGATIONS Haemoglobin was $13.6 \%$, white cell count $10,800 /$ c.mm., with normal differential; blood urea and electrolytes were normal; $\mathrm{Ca} 9.1 \mathrm{mg} . \%$, P. $3.0 \mathrm{mg} . \%$ alkaline phosphatase $8 \mathrm{King}$ Armstrong units; total serum proteins $7 \cdot 2 \mathrm{~g} . \%$, with normal albumin and globulin; serum iron $155 \mu \mathrm{g} . \%$, unsaturated ironbinding capacity $83 \mu \mathrm{g} . \%$, serum $\mathrm{B}_{12} 355 \mu \mu \mathrm{g} . / \mathrm{ml}$., no excess of formamino glutamic acid in the urine.

Stools They were pale yellow and bulky with a curious 'cheesy' smell. On a five-day faecal save, the average fatty acid content was $3.0 \mathrm{~g}$. per day (total weight of save $1,847 \mathrm{~g}$.).

Jejunal biopsy The specimen obtained (using a Crosby capsule and $x$-ray screening) had a dissecting microscope appearance of finger and leaf-like villi, within normal limits (Fig. 1). Histology showed some irregular shaped villi, but otherwise appearances were within normal limits (Fig. 2).

Electron microscopy showed that the ultrastructure of the epithelial cells was normal, and that in particular the microvilli were normal.

Radiology A small bowel meal using barium sulphate (Micropaque) alone was normal. When $25 \mathrm{~g}$. of sucrose was added to the barium mixture the appearances were grossly abnormal (Laws and Neale, 1966). The small intestine appeared distended by dilute contrast medium. The contrast medium reached the caecum rapidly, within about $40 \mathrm{~min}$., and peristalsis appeared active. The radiographic appearances after a lactose-barium meal were normal.

Disaccharide levels The results of these, using the methods of Dalqvist (1961) and Plotkin and Isselbacher (1964), are set out in Table I.

Disaccharide tolerance tests (see Fig. 4) Following the ingestion of $50 \mathrm{~g}$. of sucrose the patient had a marked exacerbation of symptoms one and a half hours later.

From the last three tests it was concluded that the patient had an isolated deficiency of sucrase and isomaltase in the intestinal epithelial cells.

Stool weights The stool weights averaged about $650 \mathrm{~g}$. while the patient was on an ordinary ward diet (Fig. 4). The stools were always acid, ranging from $p \mathrm{H} 4.5$ to 5.5 but falling to $p \mathrm{H} 4.2$ after the sucrose load. 


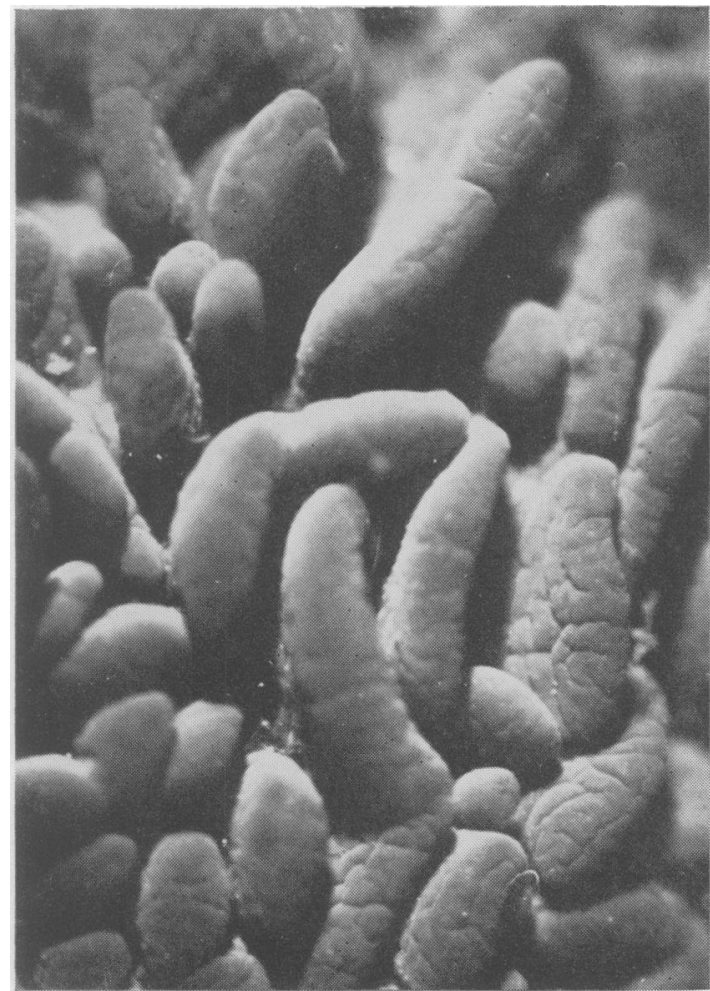

FIG. 1. Dissecting microscope appearance of the jejunal mucosa, showing finger and leaf-like villi.

TABLE I

\begin{tabular}{lccl} 
& \multicolumn{2}{c}{ DISACCHARIDE LEVELS } \\
& Patient & $\begin{array}{l}\text { Normal Controls } \\
\text { (Range) }\end{array}$ & $\begin{array}{l}\text { Normal Controls } \\
(\text { Mean })\end{array}$ \\
\hline Lactase & $24 \cdot 0$ & $4-26$ & $11 \cdot 6$ \\
Maltase & $30 \cdot 4$ & $21-132$ & $60 \cdot 5$ \\
Sucrase & 0 & $14-48$ & $23 \cdot 0$ \\
Isomaltase & $0 \cdot 2$ & - & - \\
Palatinase & 0 & - & -
\end{tabular}

I All disaccharide levels are expressed in $\mu \mathrm{m}$. of substrate hydrolysed per g. wet weight per min. at $37^{\circ} \mathrm{C}$.

The controls are the figures obtained in our laboratory on 58 adult patients with normal morphological jejunal biopsies and no evidence of a disaccharidase deficiency.

Stool culture Culture of the stools anaerobically yielded an almost pure culture of a lactobacillus. In order to try and find out whether it was this altered colonic flora or the osmotic effect of sucrose and low molecular weight acids which cause the diarrhoea, we gave the patient a week's course of tetracycline $250 \mathrm{mg}$. q.d.s. On this drug the lactobacillus in the stool was eliminated but the number of stools per day and the stool weights did not alter significantly (see Fig. 4).

Management of the patient consisted first in trying replacement therapy with Bi-myconase, a commercial preparation of sucrase and amylase, and secondly in

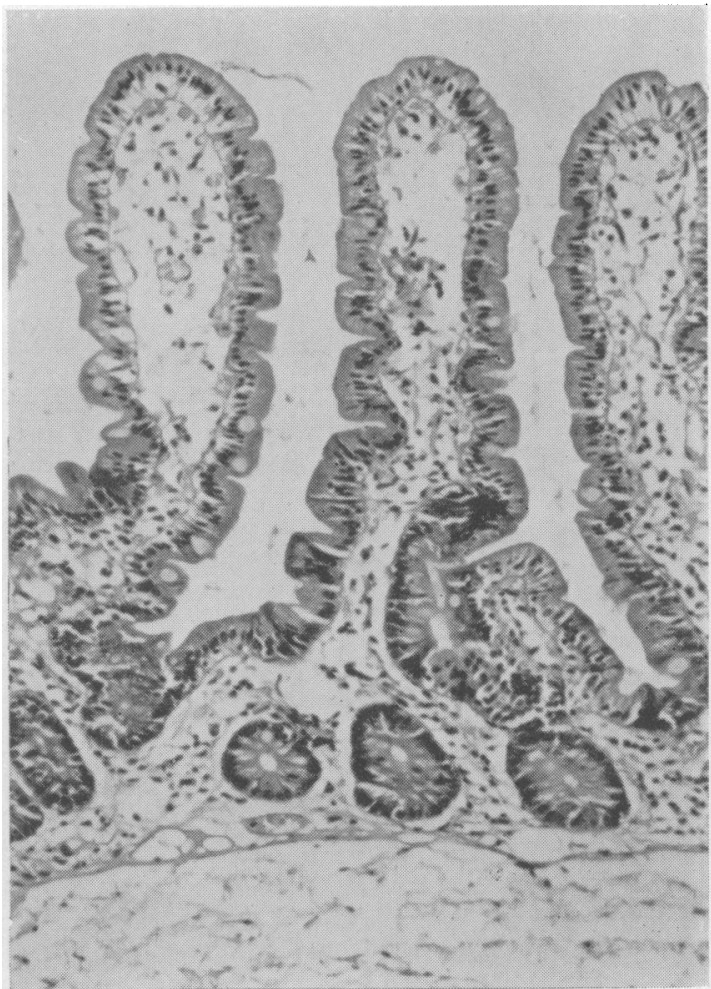

FIG. 2. Histology of jejunal mucosa, appearances within normal limits.

trying a diet without sucrose and low in starch. Taking Bi-myconase the patient was symptomatically improved, the numbers of stools per day fell from between three and six to one or two, she had less rumbling in the abdomen, and the daily stool weights were reduced (see Fig. 4).

She was then put on a sucrose-free diet with a restricted starch intake. There was even greater improvement in symptoms on this diet, with only one normal stool per day with normal stool weights (Fig. 4) and no abdominal pain or discomfort. The patient commented that she had not realized what it was like to be so completely symptomfree.

\section{DISCUSSION}

There are several features of importance in this case.

The age of onset of symptoms was 4-5 years and the patient was apparently able to tolerate sucrose well until this age. This contrasts with the cases of inherited sucrase deficiency described by Anderson et al. (1963) when symptoms began as soon as sucrose was introduced into the diet of the infant. These two patients were siblings, suggesting a genetic factor in the aetiology of the deficiency. There was no suggestion that anyone else in the family of our patient had any intolerance to sucrose. Our patient 


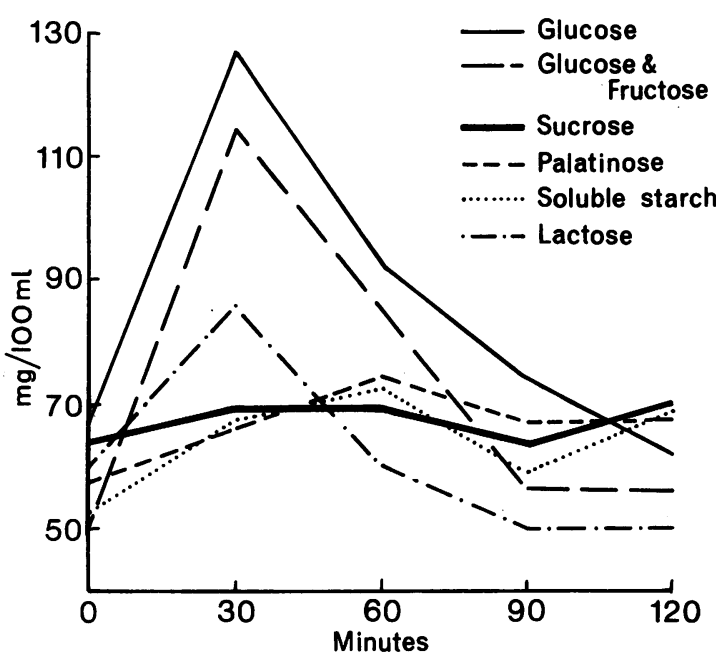

FIG. 3. Graph to show the rise in blood glucose in mg. per $100 \mathrm{ml}$. following ingestion of $50 \mathrm{~g}$. of various sugars.

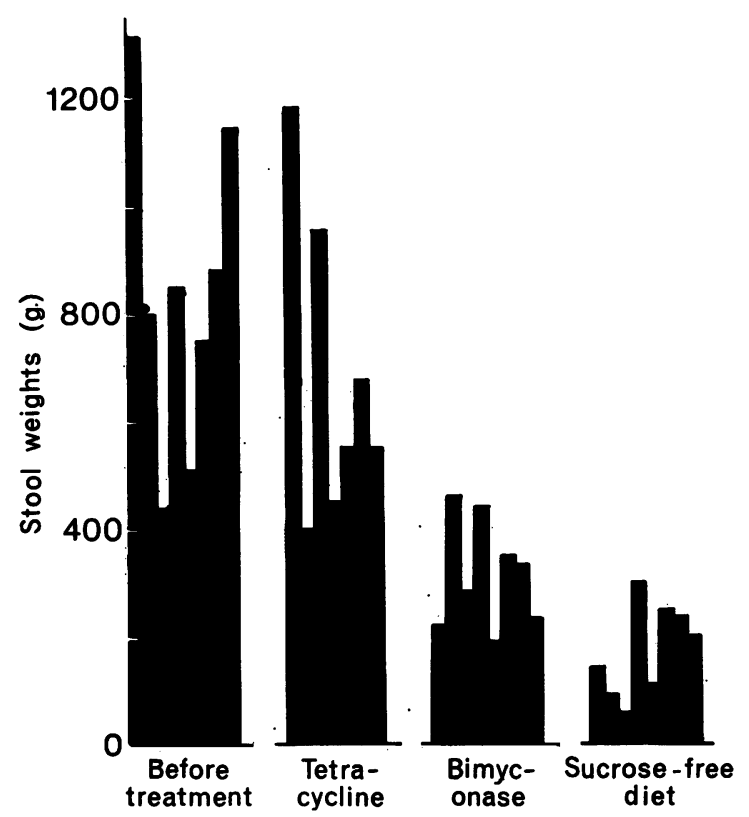

FIG. 4. Diagram to show daily stool weights before treatment and after different régimes of treatment. also contrasts with the cases of inherited enzyme deficiency in that in the latter the symptoms tend to improve spontaneously in later childhood, whereas in this case the symptoms developed in childhood, and persisted. Our patient is similar to other cases described (Neale, Clark, and Levin, 1965; Sonntag, Brill, Troyer, Welsh, Semenza, and Prader, 1964; Jansen, Que, and Veeger, 1965; Welsh and Brown, 1966), where the patients were apparently able to tolerate sucrose well for a variable period in early life, but later developed an intolerance to it.

The enzyme levels in the intestinal mucosa showed a complete absence of sucrase and an almost complete absence of isomaltase, but the other enzyme levels were well within normal limits. This contrasts with the case described by Neale et al. (1965) where the lactase level was at the borderline between low and normal, and where the lactosebarium meal also showed borderline changes in the small bowel (Laws and Neale, 1966).

It remains a curious unexplained fact that some patients with a disaccharide deficiency have very few symptoms whilst others are quite severely troubled with diarrhoea. In this patient we tried to elucidate the cause of the diarrhoea, which might be due to osmotic effects of sucrose and low molecular weight acids in the distal small bowel and colon, or might be due to altered colonic flora. The colonic flora in this case was predominantly a lactobacillus. This was eliminated by a week's course of tetracycline, but there was no change in frequency of bowel action or in stool weights. This suggests that the diarrhoea was more likely to be caused by increased osmotic effects of undigested or partially digested sucrose than to altered colonic flora.

This enzyme deficiency, although only rarely reported, may be more common than at present suspected. The 'cheesy' smell of the stools was very striking, and was also noted by Neale et al. (1965) in their patient. This, and the fairly simple radiological investigation described by Laws and Neale (1966), may lead to the more frequent diagnosis of this enzyme deficiency.

As regards management of this condition, theoretically it should be possible to treat these patients with enzyme replacement as sucrase is not destroyed by gastric juice. However, in this patient, although there was some improvement on $\mathrm{Bi}$ myconase, the effect of eliminating sugar from the diet was much more striking and brought about a dramatic improvement in symptoms. She does not find much difficulty in avoiding sweetened foods.

\section{SUMMARY}

A further case of intestinal sucrase-isomaltase deficiency presenting in an adult is described. 
It is apparently an 'acquired' defect. Features of this case are compared with others recorded in the literature, and some further investigations which may help in diagnosing the enzyme deficiency and in understanding the cause of the symptoms are described.

I would like to thank Dr. B. Creamer under whose care this patient was admitted, for his help and encouragement in the preparation of this paper; and also Mr. P. Leppard and Miss J. Cole for technical help.

The work was supported by a grant from St. Thomas' Hospital Endowment Fund.

\section{REFERENCES}

Anderson, C. M., Messer, M., Townley, R. R. W., and Freeman, M. (1963). Intestinal sucrase and isomaltase intolerance in 2 siblings. Pediatrics, 31, 1003-1010.

Dalqvist, A. (1961). Determination of maltase and isomaltase activities with a glucose-oxidase reagent. Biochem. J., 80, 547-551.
Haemmerli, U. P., Kistler H., Ammann, R., Marthaler, T., Semenza, G., Auricchio, S., and Prader, A. (1965). Acquired milk intolerance in the adult caused by lactase malabsorption due to a selective deficiency of intestinal lactase activity. Amer. J. Med., 38, 7-30.

Jansen, W., Que, G. S., and Veeger, W. (1965). Primary combined saccharase and isomaltase deficiency: report of two adult siblings of consanguineous parentage. Arch. intern. Med. 116, 879-885.

Laws, J. W., and Neale, G. (1966). Radiological diagnosis of disaccharidase deficiency. Lancet, 2, 139-143.

Neale, G., Clark, M., and Levin, B. (1965). Intestinal sucrase deficiency presenting as sucrose intolerance in adult life. Brit. med. J., 2, 1223-1225.

Plotkin, G. R., and Isselbacher, K. J. (1964). Secondary disaccharidase deficiency in adult celiac disease (nontropical sprue) and other malabsorption states. New Engl. J. Med., 271, 1033-1037.

Sonntag, W. M., Brill, M. L., Troyer, W. G., Jr., Welsh, J. D., Semenza, G., and Prader, A. (1964). Sucrose-isomaltose malabsorption in an adult woman. Gastroenterology, 47, 18-25.

Townley, R. R. W. (1966). Disaccharidase deficiency in infancy and childhood. Pediatrics, 38, 127-141.

Weijers, H. A., van de Kamer, J. H., Dicke, W. K., and Ijsseling, J. (1961). Diarrhoea caused by deficiency of sugar splitting enzymes. I. Acta paediat. (Uppsala), 50, 55-71.

Welsh, J. D., and Brown, R. C. (1966). Sucrase-palatinase deficiency. Lancet, 2, 342-343. 